\title{
Rural-urban disparities in stage of breast cancer at diagnosis in Australian women
}

Short title: Rural-urban breast cancer stage

\section{Janni Leung, ${ }^{12}$ Jennifer Martin, ${ }^{34}$ Deirdre McLaughlin, ${ }^{1}$}

${ }^{1}$ School of Public Health, The University of Queensland, Australia

${ }^{2}$ Policy and Epidemiology Group, Queensland Centre for Mental Health Research, Australia

${ }^{3}$ School of Medicine, The University of Queensland, Australia

${ }^{4}$ School of Medicine and Public Health, University of Newcastle, Australia

\section{Corresponding author}

Janni Leung, School of Public Health, The University of Queensland, Queensland, Australia. Tel: +61433655335. Fax: +61733655540; E-mail: j.leung1@uq.edu.au

Key words: rural health; urban-rural differences; breast cancer; stage of disease; early detection; body mass; obesity
Abstract: 229 words
Main text: 1686 words

\section{Authorship quantification:}

i) Substantial contributions to the conception or design of the work; or the acquisition, analysis, or interpretation of data for the work; $\mathrm{JL}=60 \%, \mathrm{JM}=10 \%, \mathrm{DM}=30 \%$

ii) Drafting the work or revising it critically for important intellectual content; JL $=50 \%, \mathrm{JM}=25 \%, \mathrm{DM}=25 \%$

iii) Final approval of the version to be published; $\mathrm{JL}=33 \%, \mathrm{JM}=33 \%, \mathrm{DM}=33 \%$

i) Agreement to be accountable for all aspects of the work in ensuring that questions related to the accuracy or integrity of any part of the work are appropriately investigated and resolved. $\mathrm{JL}=33 \%, \mathrm{JM}=33 \%, \mathrm{DM}=33 \%$

This is the author manuscript accepted for publication and has undergone full peer review but has not been through the copyediting, typesetting, pagination and proofreading process, which may lead to differences between this version and the Version of Record. Please cite this article as doi: $10.1111 /$ ajr.12271

This article is protected by copyright. All rights reserved 


\section{Acknowledgements}

The research on which this paper is based was conducted as part of the Australian Longitudinal Study on Women's Health, the University of Newcastle and the University of Queensland. We are grateful to the Australian Government Department of Health and Ageing for funding and to the women who provided the survey data. We thank Annette Dobson and Samantha McKenzie for their comments on the early stages of the research. The authors thank the NSW Ministry of Health, the NSW Central Cancer Registry and staff at the Centre for Health Record Linkage (CHeReL). The authors wish to thank the staff and the data custodians of the Queensland Cancer Registry. The authors thank staff at The Cancer Council Victoria. The funding source had no role in the design, conduct, and reporting of the study.

\section{Conflict of interests}

The authors declare that they have no conflict of interest.

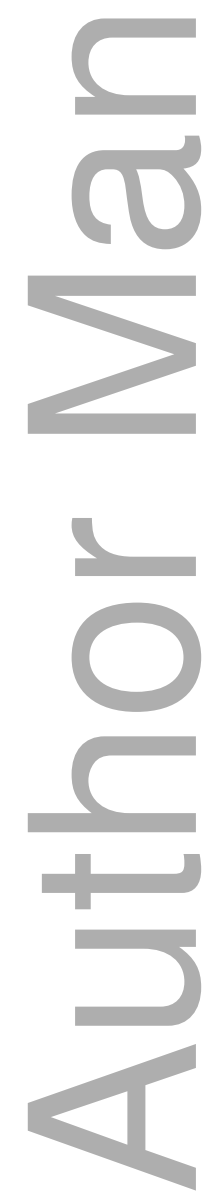


Received Date : 06-Jun-2015

Revised Date : 21-Sep-2015

Accepted Date: $21-$ Oct-2015

Article type : Original Research

\section{Rural-urban disparities in stage of breast cancer at diagnosis in Australian women}

Breast cancer survival rates are highly dependent on the stage of breast cancer diagnosis, with five year survival rates ranging from $88 \%$ to $93 \%$ in women diagnosed at an early stage, to $15 \%$ to $78 \%$ in women diagnosed at an advanced stage. ${ }^{1}$ Rurality of residence has previously been identified as a risk factor for a late stage of breast cancer diagnosis in an Australian study. ${ }^{2}$ However, due to the lack of data, the study was unable to adjust for individual-level risk factors, such as birth in a non-English speaking country, menopausal status, and poor lifestyle. ${ }^{3-6}$ While population-based cancer registries can provide objective information on key breast cancer characteristics, data on individual and contextual variables, albeit known to be risk factors, are not available in these datasets. Consequently, existing Australian-based research, which relies solely on cancer registry data, is limited in its ability to provide a comprehensive profile of the factors associated with a late stage at breast cancer diagnosis.

The linking of both cancer registry data and data drawn from population-based epidemiological studies can thus provide a comprehensive profile of women who are diagnosed with a late stage of breast cancer. The aim of the current study is to use data from the Australian Longitudinal Study on Women's Health and linked data from Australian State-based cancer registries to examine risk factors for a late stage of breast cancer at diagnosis.

\section{Methods}

\section{Survey design}

The Australian Longitudinal Study on Women's Health (ALSWH) is a prospective study of factors affecting the health and well-being of three cohorts of women who were aged 18-23 years (1973-1978 cohort), 45-50 years (1946-1951 
cohort) and 70-75 years (1921-1926 cohorts) at the time of Survey 1 in 1996. Women were selected from the Australian national health insurance database (Medicare), which includes all citizens and permanent residents. Stratified random sampling was used with intentional over-sampling of women from rural and remote areas. The project uses mailed questionnaires to collect self-report data on health and related variables every three years. Retention rates were high, ranging from $82 \%-91 \%$. Details have been described elsewhere. ${ }^{7}$ Linked cancer registry data were available from three Australian states: New South Wales, Queensland, and Victoria. Seventy five percent of the ALSWH sample resided in these states.

\section{Participants}

Participants were drawn from the ALSWH 1946-1951 cohort. Diagnosis of breast cancer was obtained from cancer registry data from New South Wales (New South Wales Cancer Registry linked by the Centre for Health Record Linkage [CHeReL]), Queensland (Queensland Cancer Registry), and Victoria (The Cancer Council Victoria) for the period 1997 to 2011. Participants were identified as breast cancer cases if they had an International Classification of Diseases (ICD-10) diagnosis of breast cancer (C50) in the cancer registry datasets. Date and stage at diagnosis were drawn from cancer registry datasets. To date, six surveys of the ALSWH data have been collected from this cohort (surveyed in 1996, 1998, 2001, 2004, 2007, and 2010). The ALSWH data, including covariates, used in analyses were drawn from surveys preceding the date of diagnosis recorded in the cancer registry. For instance, if a woman was diagnosed in 2006, her ALSWH data would be drawn from the 2004 survey.

The flowchart of participant inclusion is shown in Figure 1. From the 13,715 women who responded to survey 1 of the ALSWH, 313 women were diagnosed with breast cancer. The incidence was estimated to be 203.3 per 100,000 women, which corresponds to the Australian population incidence of 184.3-334.9 per 100,000 women. ${ }^{8}$ The final sample included 195 women with complete data (see Figure 1).

$<$ Please insert Figure 1 here>

\section{Outcome variable}

Breast cancer stage at diagnosis was the outcome variable. It was defined using internationally recognised TNM Classification of Malignant Tumors, based on tumor 
size $(\mathrm{T})$, lymph node involvement $(\mathrm{N})$ and metastases $(\mathrm{M}) .{ }^{9}$ Breast cancer stage at diagnosis was categorized by defining stage I as 'early' (localised; tumour size 20mm or smaller without positive nodes), and stage II, III, or IV as 'late'.

\section{Explanatory variables}

Rural-urban area of residence was categorised based on the Accessibility/Remoteness Index of Australia Plus (ARIA+). ${ }^{10}$ Major cities were defined as 'urban'. Inner regional, outer regional, and remote or very remote areas were combined due to small numbers and were defined as 'rural'.

Individual-level characteristics variables included country of birth ('Australia', 'other English speaking countries', and 'non-English speaking countries'), highest educational qualification completed ('school certificate', 'higher school, trade, certificate, or diploma', and 'university or higher'), marital status ('partnered' [married or living with a partner] and 'not partnered' [separated, divorced, never married, or widowed], body mass index (BMI; $<25=$ 'underweight or normal' 25 to $<30=$ 'overweight', $\geq 30$ = 'obese'), ${ }^{11}$ smoking ('never', 'ex-smoker', or 'current smoker'), menopausal status ('surgical menopause', 'hormone replacement therapy or oral contraceptive pill use [HRT or OCP]', 'Pre', 'Peri', and 'Post' menopausal). ${ }^{12}$

\section{Statistical analysis}

Firstly, descriptive statistics of pre-diagnosis characteristics of participants were presented. Second, cross-tabulations were conducted between the stages of breast cancer at diagnosis by rural-urban residence and the individual explanatory variables. The percentages, and $95 \%$ confidence intervals (95\% CI), of women with an early stage compared to a late stage of breast cancer at diagnosis were estimated by area of residence and individual explanatory variables. Univariate significance was tested by conducting chi-squared analyses. Finally, a multivariate binary logistic regression analysis was conducted to estimate the adjusted odds ratio (OR) of a late stage of breast cancer at diagnosis, compared to an early stage as the reference category. The odds of a late stage of breast cancer among women living in rural areas were estimated, compared to women living in urban areas. In addition, the multivariate analysis examined the odds of a late stage of breast cancer by individual explanatory variables, which included country of birth, education, marital status, BMI, smoking status, and menopause status 
before diagnosis. Year of diagnosis and year of birth were entered as control variables. All analyses were conducted using SPSS 18.0.

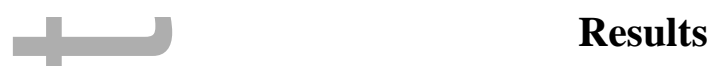

Characteristics of participants pre-diagnosis are shown in Table 1. Overall, thirty-nine percent of women had a late stage of breast cancer at diagnosis. The majority of women were born in Australia and were partnered. Forty-four percent of women had a normal BMI, 29\% were overweight, and $27 \%$ were obese. Half of the women had never smoked and over half of the women were post-menopausal.

$<$ Please insert Table 1 here $>$

The cross-tabulation results showed that in rural areas, $40 \%$ of women with breast cancer were diagnosed at a late stage, compared to $36 \%$ in women residing in urban areas. However, univariate chi-squared test results did not reach statistical significance, $\chi^{2}=0.27, p=.607$ (see Table 2). A chi-squared test did however showed that stage of breast cancer at diagnosis significantly differed by BMI, $\chi^{2}=4.24, \mathrm{p}=$ 0.044. A late stage was more common in women who were overweight (42\%) or obese (47\%), compared to women who were normal weight (31\%). Stage of breast cancer at diagnosis did not differ significantly by any other individual explanatory variables analysed.

\section{$<$ Please insert Table 2 here $>$}

Results of the multivariate logistic regression showed that women residing in rural areas were not significantly at higher odds of being diagnosed with a late stage of breast cancer (adjusted $\mathrm{OR}=1.08,95 \% \mathrm{CI}=0.53-2.23$ ). The strongest risk factor for a late stage of breast cancer at diagnosis was obesity. Women who were obese (adjusted $\mathrm{OR}=2.70,95 \% \mathrm{CI}=1.18-6.17$ ) had significantly higher odds of being diagnosed at a late stage compared to women who were in the underweight or normal BMI range.

\section{$<$ Please insert Table 3 here $>$}

Following the above interesting result of BMI as a risk factor for a late stage of breast cancer at diagnosis, rather than rural-urban residence, post-hoc analyses was conducted to further investigate the relationship between BMI and stage of breast cancer at diagnosis across rural-urban residence. Figure 2 presents the percentage of women with breast cancer diagnosed at a late stage according to their BMI, stratified by rural- 
urban residence. As shown in the figure, women who were obese were more likely to be at a late stage of breast cancer at diagnosis in both the urban and rural sample.

$<$ Please insert Figure 2 here $>$

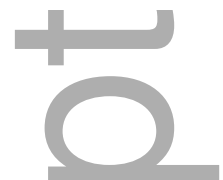

\section{Discussion}

The current study is the first Australian study that used survey data linked with cancer registry data to compare rural-urban differences in a late stage of breast cancer at diagnosis. While the percentage of breast cancer patients diagnosed at a late stage was higher in rural areas compared to urban areas this difference did not reach significance. The findings highlight the role of obesity as a more important contributor to a late stage of breast cancer at diagnosis than rurality of residence. Obesity was observed to be a risk factor for a late stage of breast cancer at diagnosis across women living in rural and urban areas

The obesity finding is consistent with previous studies on a predominantly urban sample, showing that women who were obese were more likely to be diagnosed with a late stage of breast cancer. ${ }^{13-15}$ Obesity has also been identified as a risk factor for breast cancer mortality after diagnosis, ${ }^{16}$ which suggests that breast cancer may be more aggressive in obese patients. While the rate of obesity is generally higher in rural areas, ${ }^{17}$ no previous studies comparing urban and rural differences in stages of breast cancer at diagnosis have adjusted for obesity. ${ }^{18}$ The current study highlighted that obesity, which is more common in the rural population, ${ }^{17}$ is a key risk factor for breast cancer prognosis.

The prolonged use of combination HRT (estrogen and progesterone) increases the risk of breast cancer, as well as the risk of being diagnosed with a late stage. ${ }^{19,20}$ Our findings indicated that breast cancer patients who reported HRT or OCP use were less likely to be diagnosed at a late stage. However, this evidence was weak because our sample size of women using HRT or OCP was small. Also, details of HRT type, dosage and length of use were not available. The association between menopausal status and breast cancer prognosis would be an area of future research.

Previous research has found that women with high BMI were at higher risk of an advanced stage of breast cancer only when the disease was self-detected. ${ }^{15}$ The absence of information on breast screening and the method of diagnosis in our dataset is a 
limitation. However, in a previous study based on the current sample, women with BMI in the obese range were more likely to conduct breast self-examinations with combination with mammography when compared to women with normal BMI. ${ }^{21}$ Therefore, the relationship between obesity and a later stage of breast cancer diagnosis is unlikely to be explained by a lack of mammography.

As with all survey data, self-report bias is a limitation. BMI was self-reported rather than objectively measured. Therefore some women in the overweight and obese range were likely to be misclassified into the normal BMI range. ${ }^{22}$ For these reasons, our reported effect of obesity on a late stage of breast cancer diagnosis is likely to be underestimated.

Previous research has found that ethnic minorities are more likely to be diagnosed with an advanced stage of breast cancer. ${ }^{23} \mathrm{We}$ found no differences in stage of breast cancer at diagnosis by country of birth. However, our sample was derived from a mostly white Australian population. Indigenous women represent only about $1 \%$ of the ALSWH sample ${ }^{7}$ Therefore, our findings cannot be generalised to Indigenous Australian women living in rural areas, who are likely have higher risk of advanced breast cancer at diagnosis. ${ }^{24,25}$

\section{Conclusion}

Despite an expectation that later stage at diagnosis could be explained by degree of rural residency, we found that this was not supported in an Australian population. Instead, we found that obesity was a stronger risk factor associated with a higher risk of a late stage of disease at breast cancer diagnosis, which was a shared risk factor across area of residence, and persisted after socio-demographic and individual risk factors were considered. Given that women are becoming increasingly obese, ${ }^{26}$ and that the rate of obesity is higher in the Australian rural population, this paper provides further evidence for targeting interventions for obesity, particularly in rural Australia, as a public health priority. 


\section{Conflict of interests}

The authors declare that they have no conflict of interest.

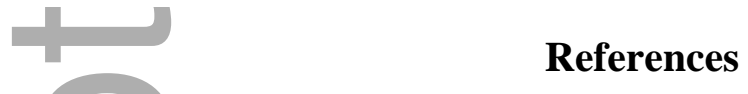

1 Australian Institute of Health and Welfare. Breast cancer survival by size and nodal status in Australia. Cancer series. Canberra: Australian Institute of Health and Welfare and National Breast Cancer Centre, 2007.

2 Baade P, Turrell G, Aitken J. Geographic remoteness, area-level socio-economic disadvantage and advanced breast cancer a cross-sectional, multilevel study. Journal of Epidemiology and Community Health 2011; 65: 1037-1043.

3 Clegg LX, Reichman ME, Miller BA, Hankey BF, Singh GK, Lin YD, et al. Impact of socioeconomic status on cancer incidence and stage at diagnosis: Selected findings from the surveillance, epidemiology, and end results: National Longitudinal Mortality Study. Cancer Causes and Control 2009; 20: 417-435.

4 Downing A, Harrison WJ, West RM, Forman D, Gilthorpe MS. Latent class modelling of the association between socioeconomic background and breast cancer survival status at 5 years incorporating stage of disease. Journal of Epidemiology and Community Health 2010 Sep; 64: 772-776.

5 Kricker A, Newman B, Gertig DM, Goumas C, Armes J, Armstrong BK. Why do large breast cancers still present in a population offered screening? International Journal of Cancer 2008; 123: 2907-2914.

6 Tracey E, Roder D, Zorbas H, Villanueva E, Jelfs P, Bishop J. Survival and degree of spread for female breast cancers in New South Wales from 1980 to 2003: implications for cancer control. Cancer Causes and Control 2008 Dec; 19: 1121-1130.

7 Lee C, Dobson AJ, Brown WJ, Bryson L, Byles J, Warner-Smith P, et al. Cohort Profile: the Australian Longitudinal Study on Women's Health. International Journal of Epidemiology 2005 Oct; 34: 987-991.

8 Australian Institute of Health and Welfare. Breast cancer in Australia: an overview, 2012. Canberra: Australian Institute of Health and Welfare 2012.

9 National Cancer Institute. Cancer Staging. National Institutes of Health, 2010. 
10 Australian Bureau of Statistics. ASGC Remoteness Classification: Purpose and Use. Census Paper. Canberra: Australian Bureau of Statistics, 2003.

11 World Health Organization. The International Classification of adult underweight, overweight and obesity according to BMI. BMI classification. Geneva: World Health Organization, 2006.

12 Berecki J, Begum N. Defining menopausal status. Technical Report 31. Brisbane: The Australian Longitudinal Study on Women's Health, 2008.

13 Cui Y, Whiteman MK, Flaws JA, Langenberg P, Tkaczuk KH, Bush TL. Body mass and stage of breast cancer at diagnosis. International Journal of Cancer 2002; 98: 279-283.

14 Hall HI, Coates RJ, Uhler RJ, Brinton LA, Gammon MD, Brogan D, et al. Stage of breast cancer in relation to body mass index and bra cup size. International Journal of Cancer 1999; 82: 23-27.

15 Reeves MJ, Newcomb PA, Remington PL, Marcus PM, MacKenzie WR. Body mass and breast cancer: relationship between method of detection and stage of disease. Cancer 1996; 77: 301-307.

16 Protani M, Coory M, Martin JH. Effect of obesity on survival of women with breast cancer: systematic review and meta-analysis. Breast Cancer Research and Treatment 2010 Oct; 123: 627-635.

17 Dobson A, McLaughlin D, Vagenas D, Wong KY. Why are death rates higher in rural areas? Evidence from the Australian Longitudinal Study on Women's Health. Australian and New Zealand Journal of Public Health 2010 Dec; 34: 624-628.

18 Nguyen-Pham S, Leung J, McLaughlin D. Disparities in breast cancer stage at diagnosis in urban and rural adult women: a systematic review and meta-analysis. Annals of Epidemiology 2014 Mar; 24: 228-235.

19 Chlebowski RT, Anderson G, Pettinger M, Lane D, Langer RD, Gilligan MA, et al. Estrogen plus progestin and breast cancer detection by means of mammography and breast biopsy. Archives of Internal Medicine 2008 Feb 25; 168: 370-377; quiz 345. 
20 Marjoribanks J, Farquhar C, Roberts H, Lethaby A. Long term hormone therapy for perimenopausal and postmenopausal women. Cochrane Database of Systematic Reviews 2012; 7: CD004143.

21 Leung J, McKenzie S, Martin J, Dobson A, McLaughlin D. Longitudinal patterns of breast cancer screening: mammography, clinical, and breast selfexaminations in a rural and urban setting. Women's Health Issues 2014 Jan-Feb; 24: e139-146.

22 Gorber SC, Tremblay M, Moher D, Gorber B. A comparison of direct vs. self report measures for assessing height, weight and body mass index: a systematic review. Obesity Reviews 2007; 8: 307-326.

23 Menck HR, Mills PK. The influence of urbanization, age, ethnicity, and income on the early diagnosis of breast carcinoma. Cancer 2001; 92: 1299-1304.

24 Valery PC, Coory M, Stirling J, Green AC. Cancer diagnosis, treatment, and survival in Indigenous and non-Indigenous Australians: a matched cohort study. The Lancet 2006; 367: 1842-1848.

25 Condon JR, Barnes T, Armstrong BK, Selva-Nayagam S, Elwood JM. Stage at diagnosis and cancer survival for Indigenous Australians in the Northern Territory. The Medical journal of Australia 2005 Mar 21; 182: 277-280.

26 Gomersall SR, Dobson AJ, Brown WJ. Weight Gain, Overweight, and Obesity: Determinants and Health Outcomes from the Australian Longitudinal Study on Women's Health. Current Obesity Reports 2014 2014/03/01; 3: 46-53.

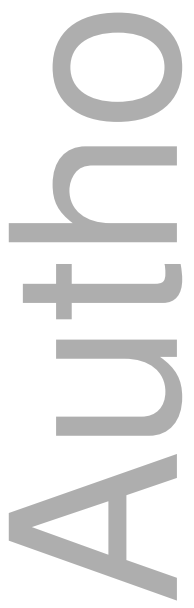


Table 1: Pre-diagnosis characteristics of participants $(\mathrm{N}=195)$

\begin{tabular}{|c|c|c|}
\hline & $\mathrm{n}$ & $\%$ \\
\hline \multicolumn{3}{|l|}{ Stage at diagnosis } \\
\hline Early & 120 & 61.5 \\
\hline Late & 75 & 38.5 \\
\hline \multicolumn{3}{|l|}{ Area of residence } \\
\hline Urban & 72 & 36.9 \\
\hline Rural & 123 & 63.1 \\
\hline \multicolumn{3}{|l|}{ Country of birth } \\
\hline Australia & 142 & 72.8 \\
\hline $\begin{array}{l}\text { Other English speaking } \\
\text { countries }\end{array}$ & 29 & 14.9 \\
\hline $\begin{array}{l}\text { Non-English speaking } \\
\text { countries }\end{array}$ & 24 & 12.3 \\
\hline \multicolumn{3}{|l|}{ Education } \\
\hline School certificate & 77 & 39.5 \\
\hline $\begin{array}{l}\text { Higher school, trade, } \\
\text { certificate, or diploma }\end{array}$ & 89 & 45.6 \\
\hline University or higher & 29 & 14.9 \\
\hline \multicolumn{3}{|l|}{ Marital status } \\
\hline Not partnered & 43 & 22.1 \\
\hline Partnered & 152 & 77.9 \\
\hline \multicolumn{3}{|l|}{ Body mass index } \\
\hline $\begin{array}{l}\text { Underweight or normal } \\
(<25)\end{array}$ & 85 & 43.6 \\
\hline Overweight ( 25 to <30) & 57 & 29.2 \\
\hline Obese $(\geq 30)$ & 53 & 27.2 \\
\hline \multicolumn{3}{|l|}{ Smoking status } \\
\hline Never & 98 & 50.3 \\
\hline Ex-smoker & 70 & 35.9 \\
\hline Current & 27 & 13.8 \\
\hline \multicolumn{3}{|l|}{ Menopause status } \\
\hline Surgical menopause & 54 & 27.7 \\
\hline
\end{tabular}




\begin{tabular}{lll} 
HRT or OCP use & 35 & 17.9 \\
Pre & 24 & 12.3 \\
Peri & 23 & 11.8 \\
Post & 59 & 30.3 \\
\hline
\end{tabular}

HRT or OCP, hormone replacement therapy or oral contraceptive

pill
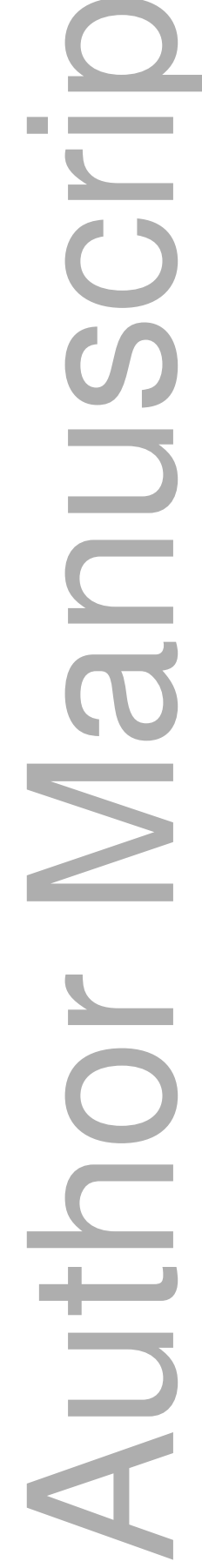

This article is protected by copyright. All rights reserved 
Table 2: Percentages (95\% confidence intervals) of women with breast cancer diagnosed at early or late stage cross-tabulated by explanatory variables $(\mathrm{N}=195)$

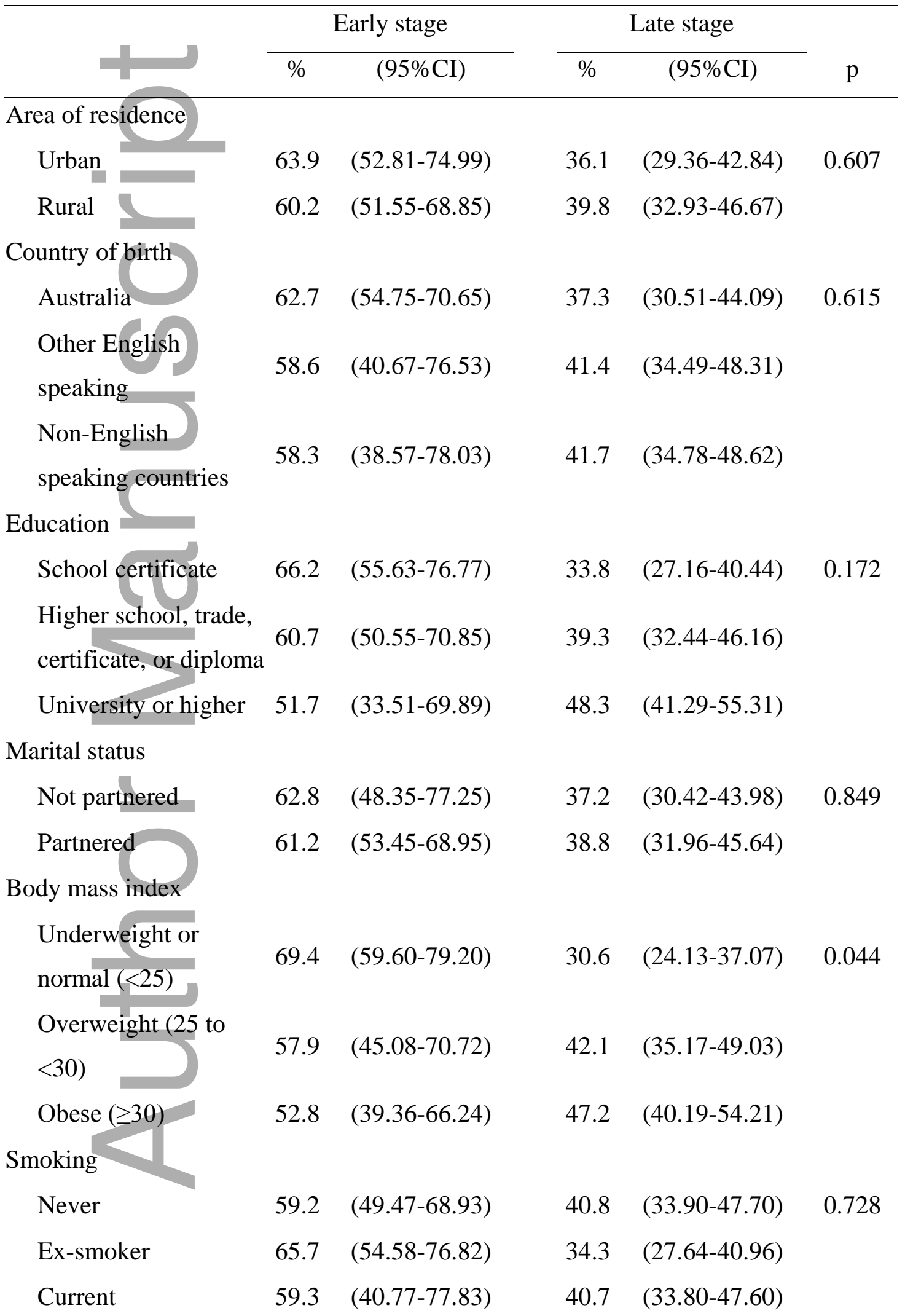


Menopause status

$\begin{array}{llllll}\text { Surgical menopause } & 46.3 & (33.00-59.60) & 53.7 & (46.70-60.70) & 0.119 \\ \text { HRT or OCP use } & 77.1 & (63.18-91.02) & 22.9 & (17.00-28.80) & \\ \text { Pre } & 54.2 & (34.27-74.13) & 45.8 & (38.81-52.79) & \\ \text { Peri } & 52.2 & (31.79-72.61) & 47.8 & (40.79-54.81) \\ \text { Post } & 72.9 & (61.56-84.24) & 27.1 & (20.86-33.34) & \end{array}$

p values were calculated by univariate chi-squared tests; HRT or OCP, hormone replacement therapy or oral contraceptive pill

Table 3: Multivariate logistic regression results showing adjusted odds ratios (95\% confidence intervals) of late stage of breast cancer at diagnosis by explanatory variables with early stage as the reference category $(\mathrm{N}=195)$

\begin{tabular}{|c|c|c|}
\hline T & OR & $95 \% \mathrm{CI}$ \\
\hline \multicolumn{3}{|l|}{ Area of residence } \\
\hline Urban & 1.00 & \\
\hline Rural & 1.08 & $(0.53-2.23)$ \\
\hline \multicolumn{3}{|l|}{ Country of birth } \\
\hline Australia & 1.00 & \\
\hline Other English speaking & 1.05 & $(0.42-2.67)$ \\
\hline Non-English speaking countries & 1.42 & $(0.51-3.97)$ \\
\hline \multicolumn{3}{|l|}{ Education } \\
\hline School certificate & 1.00 & \\
\hline $\begin{array}{l}\text { Higher school, trade, certificate, or } \\
\text { diploma }\end{array}$ & 1.71 & $(0.83-3.53)$ \\
\hline University or higher & 2.20 & $(0.80-6.03)$ \\
\hline \multicolumn{3}{|l|}{ Marital status } \\
\hline Not partnered & 1.00 & \\
\hline Partnered & 1.20 & $(0.54-2.67)$ \\
\hline \multicolumn{3}{|l|}{ Body mass index } \\
\hline Underweight or normal $(<25)$ & 1.00 & \\
\hline Overweight ( 25 to $<30)$ & 1.42 & $(0.65-3.11)$ \\
\hline
\end{tabular}


Smoking

Never

Ex-smoker

Current

Menopause status

Surgical menopause

HRT or OCP use

Pre

Peri

Post
1.00

0.68

0.80

(0.30-2.17)

(1.14-6.99)

0.73

(0.24-2.20)

1.86

(0.54-6.40)

2.24

(0.71-7.11)

1.00

$\mathrm{OR}=$ adjusted odds ratio of a late stage of breast cancer at diagnosis (early stage as reference); variables in the multivariate analysis included year of diagnosis, year of birth, country of birth, education, marital status, area of residence, body mass index, smoking, and menopause status; HRT or OCP, hormone replacement therapy or oral contraceptive pill

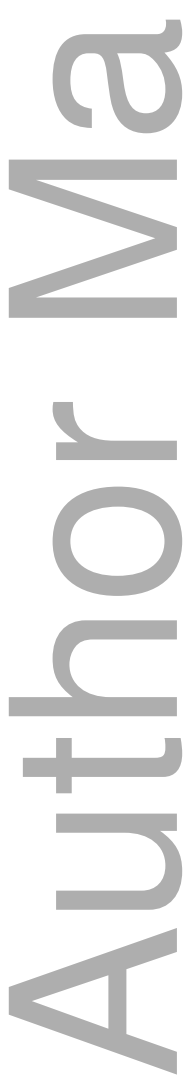




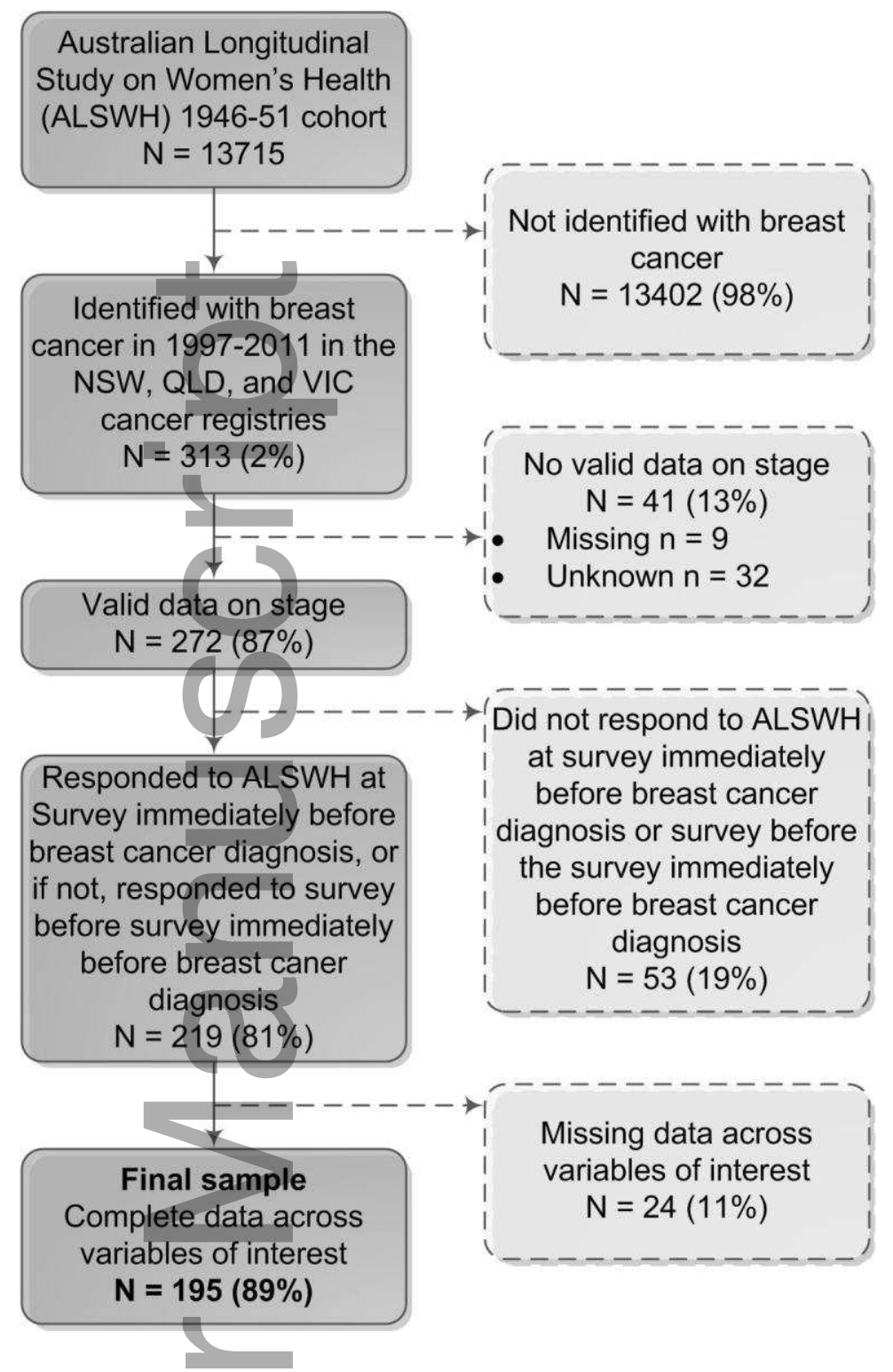

\section{Figure 1. Flowchart of participant inclusion}

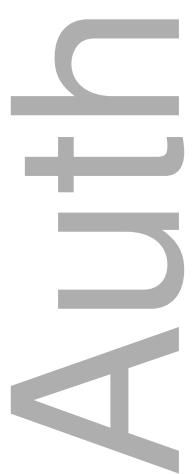

This article is protected by copyright. All rights reserved 


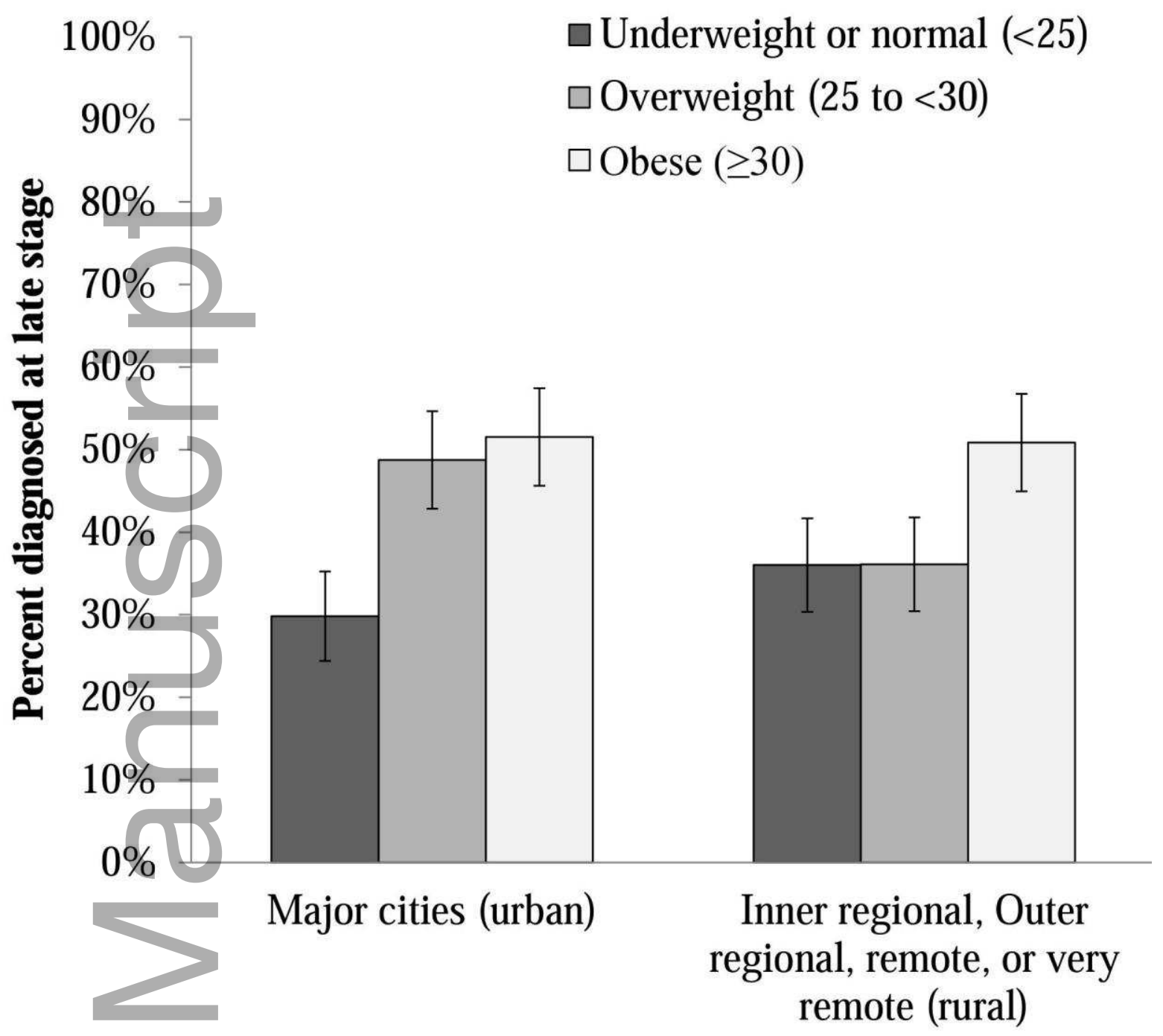

Figure 2. Percentage of women living in urban and rural areas with late stage of breast cancer at diagnosis by body mass index

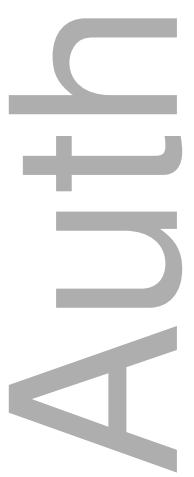




\section{University Library}

\section{- M M I N E R VA A gateway to Melbourne's research publications}

Minerva Access is the Institutional Repository of The University of Melbourne

Author/s:

Leung, J;Martin, J;McLaughlin, D

Title:

Rural-urban disparities in stage of breast cancer at diagnosis in Australian women.

Date:

2016-10

Citation:

Leung, J., Martin, J. \& McLaughlin, D. (2016). Rural-urban disparities in stage of breast cancer at diagnosis in Australian women. . Aust J Rural Health, 24 (5), pp.326-332. https:// doi.org/10.1111/ajr.12271.

Persistent Link:

http://hdl.handle.net/11343/290851 